\title{
Nachweis freier Salicylsäure in Salicylaldehyd und Salicylsäure-
} Methylester. A. Schneegans und J. E. Gerock ${ }^{1}$ ) haben gefunden, dass die Violettfärbung, welche Lösungen von Salicylaldehyd und von Salicylsäure-Methyläther mit Eisenoxydsalzen geben, auf Zusatz von Aether, Chloroform, Amylalkohol, Essigäther, Schwefelkohlenstoff, Petroläther, Paraffinöl, Benzol, Toluol, Xylol verschwindet ${ }^{2}$ ), die gleiche Färbung der Salicylsäure dagegen nicht. Diese Wahrnehmung lässt sich bei Prüfungen auf die in Rede stehenden Körper zweckmässig verwerthen. Will man z. B. freie Salicylsäure im künstlichen Wintergreen-Oel nachweisen, so schüttelt

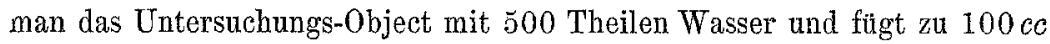
der trüben Mischung $1 c c$ Eisenchloridlösung (hundertfache Verdünuung der officinellen Lösung). Die entstehende Violettfärbung wird nach Zufügung von $5 c c$ Chloroform verschwinden, wenn das Oel säurefrei war. Enthielt dasselbe aber nur $0,2 \%$ freie Salicylsäure, so dass im Reagensglase $2 /{ }_{100} m g$ derselben vorhanden sind, so werden diese auch nach dem Schütteln mit Chloroform noch an einer auf weissem Untergrunde deutlich wahrnehmbaren Violettfärbung kenntlich sein.

Die Methode zur Untersuchung des Wollfettes, welche $\mathrm{Helb}$ ing und Passmore angegeben haben, ${ }^{3}$ ) ist von verschiedenen Seiten geprüft and als nicht brauchbar bezeichnet worden. Nach W. Graff ${ }^{4}$ ) wird Wollfett schon durch wässrige Kalilauge mehr oder minder angegriffen. Arbeitet man nach $\mathrm{He} \mathrm{l}$ bing und $\mathrm{Passmore} \mathrm{mit} \mathrm{alkoholischem}$ Kali, so erhält man unter gleichen Versuchsbedingungen zwar leidlich constante Zahlen, eine vollständige Spaltung des Wollfettes wird jedoch bei der Temperatur des Wasserbades in zwei Stunden nicht erreicht, so dass der von den oben genannten Verfassern angegebene Verseifungscoëfficient $(8,536) \mathrm{zu}$ niedrig ist.

Dies stimmt mit den älteren Angaben von Kremel überein, nach welchem 9 Theile $\mathrm{KOH}$ zur Verseifung von 100 Theilen wasserfreiem Lanolin erforderlich sind. Man kann daher Glycerinfette im Wollfett weder durch Behandlung des Untersuchungsobjectes mit wässriger Kali-

1) Journ. de Pharm. d'Alsace-Lorr, ; durch Pharm. Centralhalle 33, 40.

2) Auch das mit der wässrigen Flüssigkeit mischbare Aceton besitzt, wenn es rein ist, dieselbe Wirkung wie die oben aufgezählten, mit Wasser nicht mischbaren Flüssigkeiten.

3) Diese Zeitschrift 32, 115.

4) Pharm. Zeitung 38, 62. 